Dennis W. Jansen, an associate professor of economics at Texas A\&M University, is a visiting scholar at the Federal Reserve Bank of St. Louis. Scott Leitz provided research assistance.

\title{
Does Inflation Uncertainty Affect Output Growth? Further Evidence
}

$\mathbf{E}$ the effects of inflation on real economic vari. ables. In the past two decades, this line of research has expanded greatly, spurred on by the relatively high inflation rates in the developed economies beginning in the 1970 s and the coincident slowing in the rate of output growth. One traditional and widely accepted notion is that anticipated inflation has little or no effect on real variables, except for those effects arising from institutional features such as incompletely indexed tax codes and zero interest payments on currency and reserves. ${ }^{1}$ It is also widely accepted that unanticipated inflation affects real variables, at least in the short run.

Many analysts also hold that uncertainty about future inflation rates affects real variables. Indeed, Marshall (1886) expressed concern about the negative effects of an uncertain future value of the English pound on output over 100 years ago. More recent arguments in this spirit are contained in Okun (1971) and Friedman (1977), who argue that uncertainty about future inflation is detrimental to real economic activity.
Furthermore, they suggest that uncertainty about future inflation is linked to the mean rate of inflation by the policy environment. Friedman, in particular, argues that nations might temporarily pursue a set of goals for real variables (for example, output, unemployment) that leads to a high inflation rate. The high inflation rate induces strong political pressure to reduce it, leading to stop-go policies and attendant uncertainty about future inflation. Thus, high inflation coexists with increased inflation uncertainty, as individuals become less certain about the political choice over future inflation paths.

Friedman postulates a negative effect of a highly volatile inflation rate on economic efficiency for two reasons. First, increased volatility in inflation makes long-term contracts more costly because the future value of dollar payments is more uncertain. Second, increased volatility in inflation reduces the ability of markets to convey information to market participants about relative price movements. By reducing economic efficiency, greater inflation uncertainty should at least temporarily increase 
the rate of unemployment and reduce economic growth.? ${ }^{2}$

Though these theoretical concerns about the effect of inflation uncertainty seem reasonable and persist in economic discussions, existing studies provide only mixed support for them. This paper studies the relationships between the mean and variance of the inflation rate and output growth for the United States in another attempt to identify the hypothesized negative relationship of inflation uncertainty on output growth. To put this study into perspective, the following section briefly reviews the findings of several previous studies, with particular attention to the relationship between the measure of inflation uncertainty employed in each study and evidence about the link between inflation uncertainty and real economic variables.

\section{A REVIEW OP TTE RECENT LITERATURE}

Empirical studies of the effect of inflation uncertainty tend to follow one of three broad approaches. The first is that used by Okun (1971), who gathers data for 17 developed countries over 17 years and calculates the mean and variance of the inflation rate for each country. By plotting the mean inflation rate vs. the standard deviation of the inflation rate for these countries, he finds that these two variables are positively related. Logue and Sweeney (1981) use Okun's methodology and find that both the mean and variance of inflation are positively related to the variance of output growth. ${ }^{3}$

This approach has been criticized largely on two grounds. First the sample variance of the inflation rate for a country over 15 or 20 years is unlikely to be the best measure of uncertainty about future inflation rates, because the sam. ple variance of inflation confounds predictable and unpredictable changes in the inflation rate. For example, if the inflation rate moves in a perfectly predictable way, inflation uncertainty is zero, but the computed sample variance of inflation would be positive. A second criticism is that this approach requires a certain homogeneity across countries to make valid inferences about the variation of inflation and output growth across those countries, Gale (1981) gives reasons to doubt that this homogeneity exists, including noncomparability of indexes and different levels of development across countries. Indeed, Katsimbris (1985) strongly rejects the hypothesis of homogeneity across countries.

A second approach allows the mean and variance of inflation to change within a country through time. Katsimbris (1985) does this for 18 OECD countries. He constructs proxies for the time-varying mean and variance of inflation and output growth as eight-quarter, non-overlap. ping, moving averages. He finds few countries for which the mean and variance of inflation are related in a statistically significant way and even fewer for which the variance of inflation and the mean or variance of output growth are related. In particular, he finds no significant relationship between inflation uncertainty and output growth in the United States. Thornton (1988), in a recent study employing this methodology, obtains the same results.

Katsimbris study of individual countries is but one example of a number of studies that use this second approach. Their main feature is the construction of proxies for inflation uncertainty. In addition to Katsimbris' eight-quarter, nonoverlapping, moving averages, others estimate time series models for the inflation rate and the real variables and use the residuals to construct overlapping moving-average measures to proxy for the time-varying variance of inflation.

All of these studies lack a parametric model for the time-varying variance of inflation. For instance, Katsimbris' moving averages for the mean inflation rate does not necessarily capture the predictable elements of the inflation process. Therefore, his measure of the variance confounds the uncertainty of future inflation with predictable changes in inflation. In contrast, studies using proxies for inflation uncertainty constructed from the residuals of a model

2Recen theoretical work demonstrates that, under plausible condtions, increases in infation uncertanty lead to reductions in output. Surveys of the theoretical rationales underlying relationships between inflation uncertainty ard feal variables are contained tan Tayor (1981) and Cutierman (1983). These surveys aso discuss some of the extant empirical literalure on this topic.

proach that relates inflation and ts variability to the variabilty of production. They write, "Unfortunately, a neat measure of the next period's uncertainty that might be suitable for use in such a time series test is not avallable" (p. 499). It is a contention of this paper that the ARCH-M model provides the requisite time series test.

3Logue and Sweeney acknowledge in their text that an alternative to thetr approach is to use a time series ap- 
for the inflation process can claim rightly that they are attempting to measure only unpredictable movements in inflation; but these studies are prey to an internal inconsistency. In par. ticular, such an approach estimates a model of inflation under the maintained hypothesis of homoskedasticity and then estimates a proxy for the time-varying (heteroskedastic) conditional variance from the residuals.

A third approach to measuring inflation uncertainty uses survey data from individual inflation forecasts. A good example is Mullineaux (1980), who uses the standard deviation of individual inflation forecasts about the mean value to measure inflation uncertainty. He finds that the sum of current and lagged values of this measure of inflation uncertainty is significantly and positively related to the unemployment rate and significantly and negatively related to the level of industrial production. A more recent study by Hafer (1986) confirms these results with an alternative survey of inflation expectations.

A crucial problem with this approach, however, is that the inflation uncertainty measure actually measures the dispersion of point estimates of the inflation rate across individuals, which does not necessarily capture the degree of uncertainty about future inflation rates. Within a specific theoretical framework, cukierman (1983) has shown that these two measures are related. It is clear, however, that the individual point estimates reported in the surveys do not indicate the certainty with which individuals make their forecasts, so that measuring inflation uncertainty by the dispersion of these estimates of the inflation rate across forecasters can be misleading. ${ }^{4}$ Consider, for example, what would happen if all individuals surveyed reported the same forecast. Even if none of the individuals were very certain of the forecast, that is, if inflation uncertainty were considerable, the constructed measure would be equal to zero, ${ }^{5}$

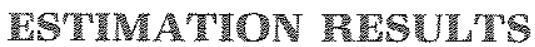

This study investigates the effects of inflation uncertainty by looking at a time series of data for the United States, following the second approach discussed above. Unlike most previous studies, however, this investigation uses a statistical technique, the ARCH model, that parameterizes the mean and variance relationships under investigation. This permits straightforward estimation and hypothesis testing in an internally consistent framework. The measure of inflation uncertainty employed here is the time. varying conditional variance of the inflation equation. A more detailed description of the class of ARCH models is provided in the shaded insert on pages 46 and 47 .

We model the inflation, real output growth system over the I/1959-II/1988 period using seasonally adjusted quarterly data on real GNP and the GNP deflator. The regression model for the conditional means of inflation and output growth is a vector autoregression.

preliminary diagnostic tests were conducted to check for unit roots and time trends in the variables. These are reported in table 1 . Neither inflation nor output growth exhibited a time trend. For output growth, the null hypothesis of a unit root was rejected. Tests for a unit root in the inflation process are inconclusive: the Dickey-Fuller test rejected the unit root hypothesis, but the augmented Dickey-Fuller test failed to do so. It is well known that tests for a unit root have low power when the alternative is a root close to but less than one. Moreover, the augmented Dickey-Fuller test is more powerful when the time series in question is not white noise after differencing, a situation that appears to hold for the GNP deflator. ${ }^{6}$ Additional infor"
4One well-known survey, the ASA-NBER survey of professional forecasters, makes an attempt to gather data on confidence bands corresponding to forecasts. These data are relatively crude, however, and are seldom used by authors invesigating the neutrality of inflation uncertainty. See, e.g. Hafer (1986).

5This is not to say that the information in the dispersion of inflation forecasts across individuals is not useful. Such information is not captured by the assumption implicit in this paper that agents forecast the inflation rate based on common information. Moreover, other approaches have been employed to look at related aspects of the relation between inflation uncertainty and real variables. Blejer and
Leiderman (1980) look at relative price variability, measured as the dispersion of price changes in a set of indusiries about the average price change of the industry. They test to see if real output and unemployment are adversely affected by increases in relative price variability. Notice that intlation uncertainty is not directly an issue in Blejer and Leiderman's work since they examine only the variability of relative prices. They report that relative price variability had significant adverse effects on real variables for the United States.

It is also known, however, that the augmented DickeyFuller tesi has lower power than the unaugmented test when the series is white noise after differencing. 


\section{The ARCH Class of Models}

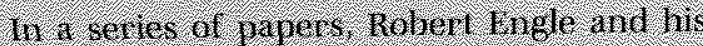

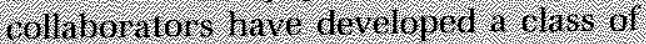

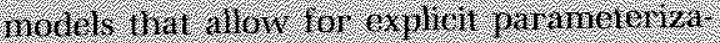

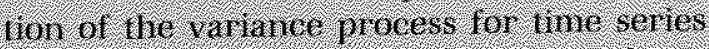
nodels. Whese noders are known by the

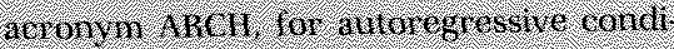

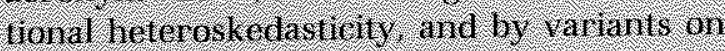

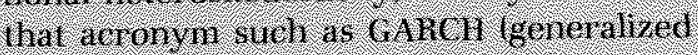

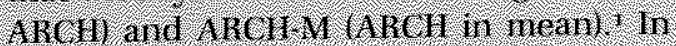

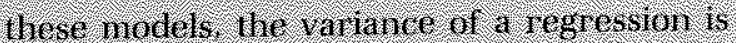
thrued ho change orer wime and. in per

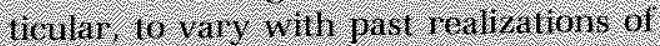

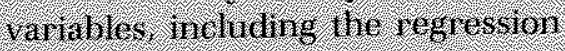

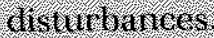

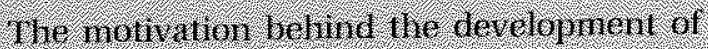

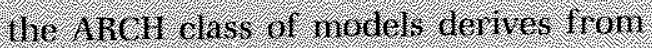

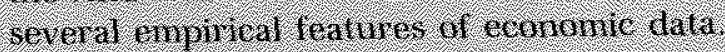
Tist the restrivive assuription of

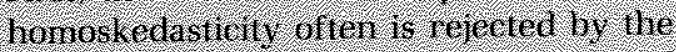

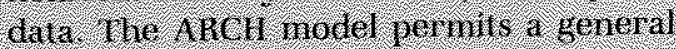

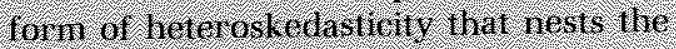

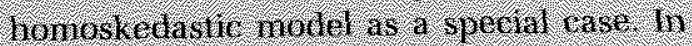

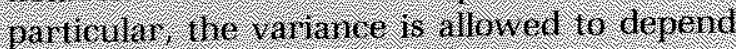

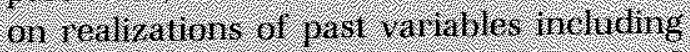

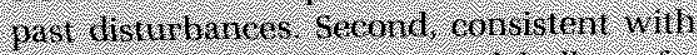

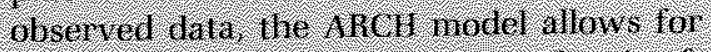

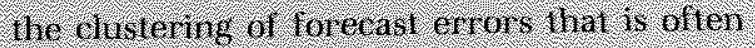

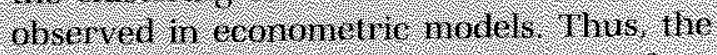

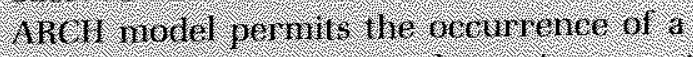

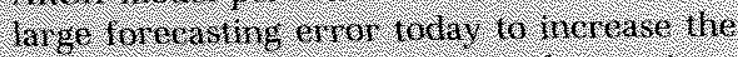

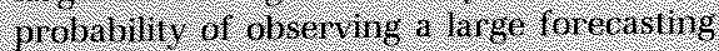

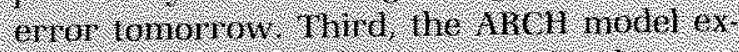

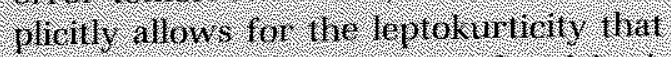

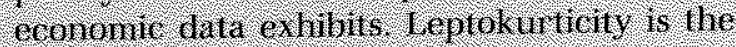

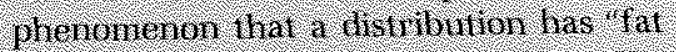

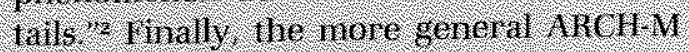

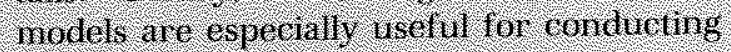

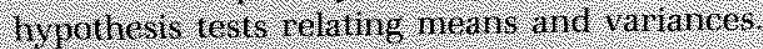

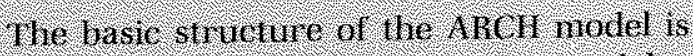

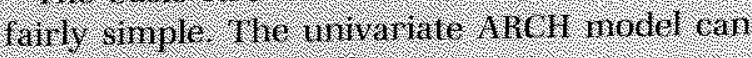
he 1 epresented as 1 lonows:

$(1)=+26+8$

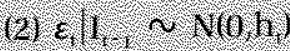

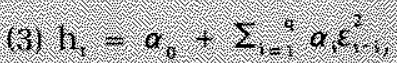
0. $>0.101,011$

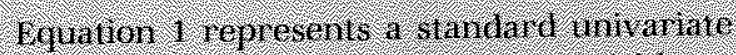

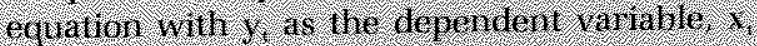

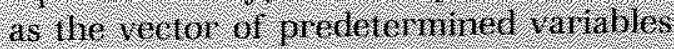
which oan indwe thes of the demendent

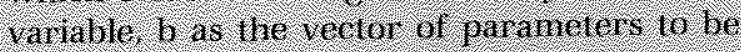

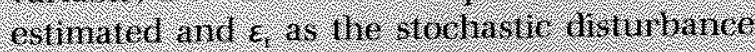

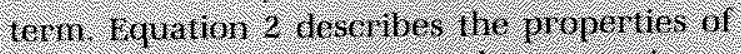

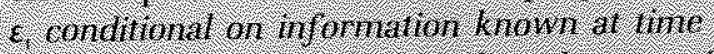

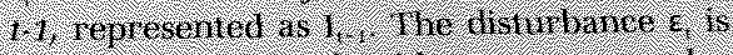
condronally nomat with nodr zoro and

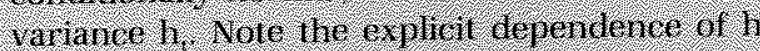

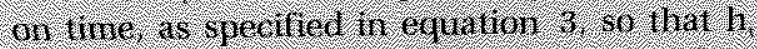

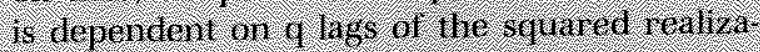

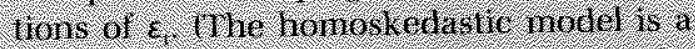

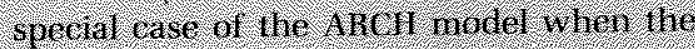

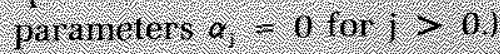

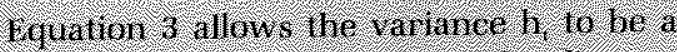

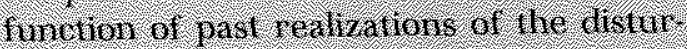

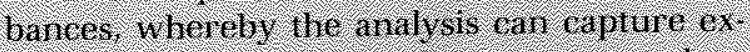

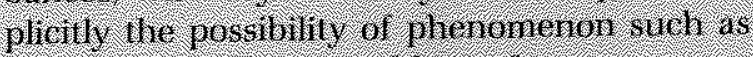

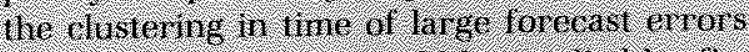

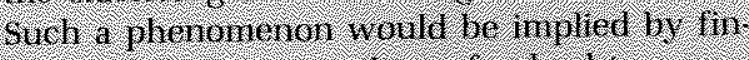

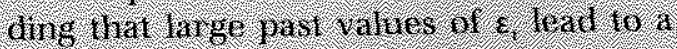

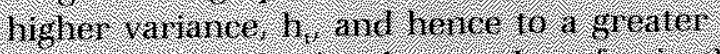

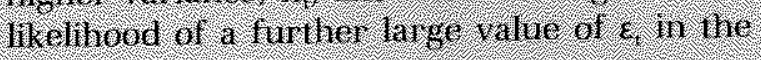
Trate

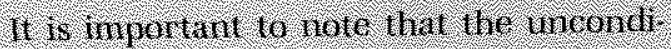

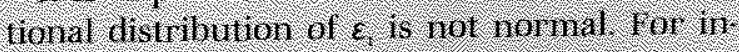

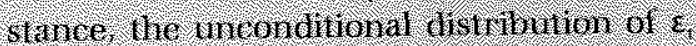

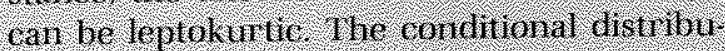

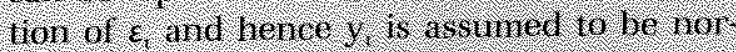

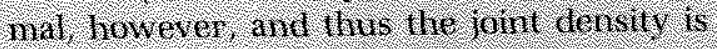

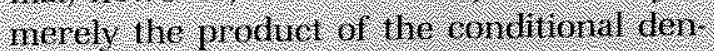

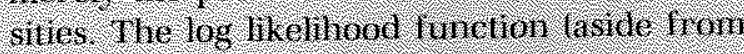
a consianl rernin is given by

$(4) 1,1,0,0)=2,1,1,1,16$

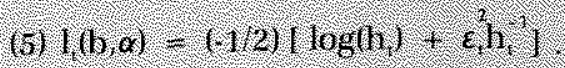

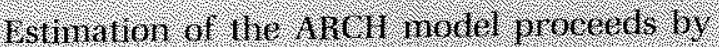

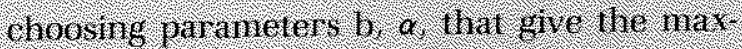

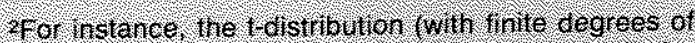

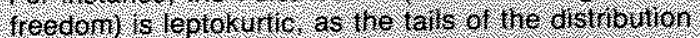

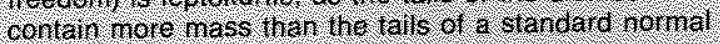
ais 1104105 
imm value for $1,(1$, a) , given the sample of $T$ obstrutions In oflet words we search for parameters 16 and a that naximize the proba bili, of haing obseried the sample Istima tim is cartied out by a numeriedl ppimiza. ten procedine. If the cerse of the ARCh model. estimation is simplified somenthat by the fact that the tho sets of parametens of b are asympitotieally independent, therelby Allowing for naminization of $1,(6$, a) with tespect to each set of parameters separately.

The Jarameters a are restricted to be positive As mandated ly lie oneticat considerations hese restrictions preclude targe revlizarions of E fom druing lhe Variance negative lor stability we also require liat die stim of the o's is less than one. Ihis is a necessam condilion tor restraining the un conditional vattance lo be finite.

in actuat applications, in is desirable to be able to test tor ARCH hefore speeifying and estimaling a noded with ARCH Thts is espe. cally true because estintiation of a model will drell involves nominear melhods lingle (1982) provides a straightforward lest, the ARCH lest based on the laggange multiplier prineple As such, in tequires onty estimates of the hmooskedastic nodel the null hypoth ests is homoskedasticity the test is conducted hy squaring the residuals from the homoskedastic nodel and regressing the squated residuals on various lags of the squared resicuals: the test statistic is the sample size tmes the $\mathrm{R}^{2}$ from this auxiliaty regression, distributed as ehi-square wili degrees of reedon equal to the number of lags of the squared residnals included in the auxiliary regression, large values lor the test statistic lead to tejection of the nill hypother sis of honoskerastieny and motudate estimation of an alit II specticatim.

An important generalization of the ARCH motel that we will employ in this paper is the anct1-V nodel, wat allows for the vart: ance term h. Io enter the regression equation for $y$. Whe $112 \mathrm{C} 11 \mathrm{M}$ moder is given by

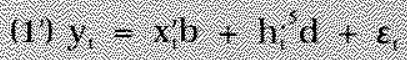

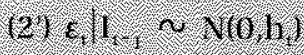

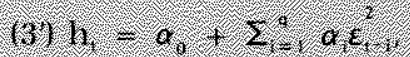
$9 .>0$ for all 1

in equation (1) d, a parameles to be esti nated, neasures the effect of the conditional ramiance on y. The lerm l. sentering equation 1 permits the condinonal vartance of lite disturbance \&; to afted the comditional

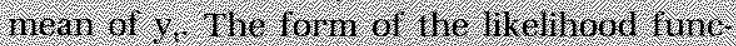
fion for his mordel is the same as lhat given in equations 1 and 5 above, hough clearly. the parameter estimates will dffer between the two nodels.

The anCI M nodel by explicity incor: porating variance neasures in the equation describing y, facilitates estimation and stalis: tical interences about the effects or varances on means. Tor our purposes, the All MI nodel iflows the explicit parameterization and estimation of ine varying inflation uncertanty defined as he conditional var. Tance of the distumbance to an equation for the inftation tate Jurther, wilh ble ARCHM generalization, we ean estimate and lest hypotheses about the efreet of the time. varving inflation uncertainty on the condi? tonal means of macroeconomic variables. such as the inflition rate itself and hie rate of growth of autput:
This hodel has been ised by Engle, Then and Robins 0987 to estmate a nodel of he term sirucurre in Which the risk prernitum is nodeled as the waryng and in which the isk prenitin affects the holding perlod
Yleld the Anch specilication provdes a way of

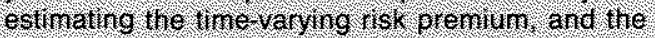
AReltil spectication ades the abiliy to estmate the eltect of the risk premilin on the expected feld? 
Table 1

Trend and Unit Root Tests Sample: 111960-11/1988

4. Unit root tests. Nill hpothesis. Varlable has a unit root

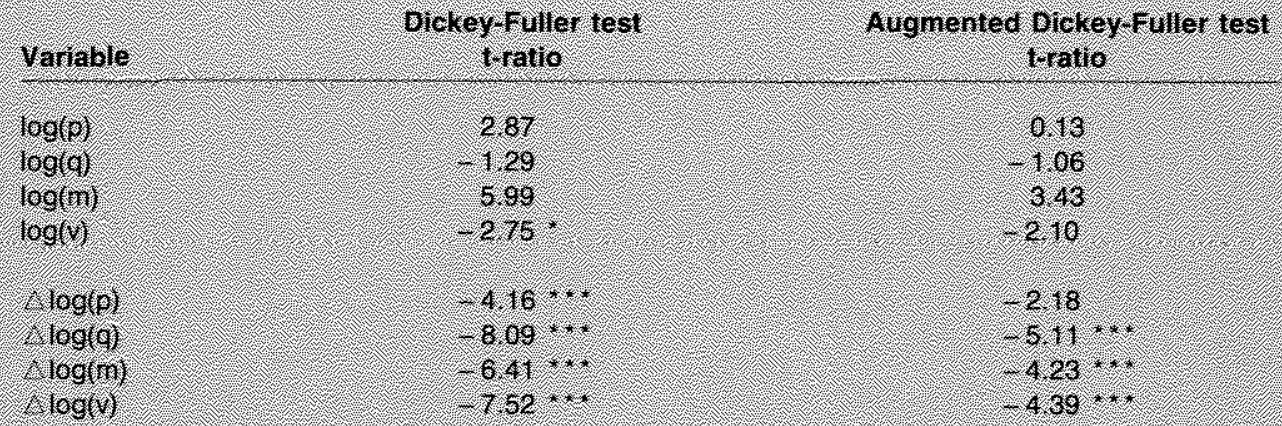

Approxinale grical valles tor rejedtho nul hypollesis.

Stgrificance

Critical value

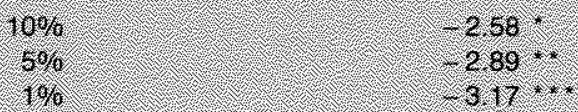

B. Tests for tme tends. Nul hypothesis Vartable has a unit root and no trend.

\begin{tabular}{|c|c|}
\hline 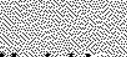 & Bickev ruller \\
\hline roglo & 4.26 \\
\hline (ogfo) & 2.98 \\
\hline 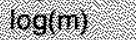 & 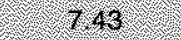 \\
\hline $\log (\mathrm{V})$ & 1.4 \\
\hline
\end{tabular}

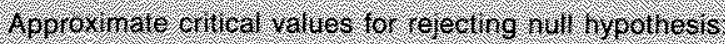

\begin{tabular}{|c|c|}
\hline Signifieanee & Critcal value \\
\hline $10 \%$ & 647 \\
\hline 56 & 6.9 \\
\hline $1 \%$ & 873 \\
\hline
\end{tabular}


mation on the hypothesis of a unit root in the inflation rate can be garnered from the empirical distributions of the Dickey-Fuller test statistic when the series has non-zero drift. These distributions have been tabulated by Schmidt (1988). For the inflation rate, the drift component would lead to a modification of the critical values tabulated by Dickey-Fuller, so that the 5 percent critical value is -2.11 and we reject the hypothesis of a unit root in the inflation series.

The lag structure of the model was specified with the aid of the FPE (or Final Prediction Error) procedure. ${ }^{8}$ Estimates of the model chosen under the assumption of homoskedasticity are provided in table 2. Diagnostic tests reported in table 3 indicate no statistically significant serial correlation and no significant evidence for a structural break in 1973, the approximate midpoint of the sample. ${ }^{9}$ The ARCH test, also reported in table 3 , rejects the null hypothesis of homoskedasticity for the inflation equation. There is little evidence for rejecting either a constant conditional variance of the disturbance to the output equation, or a constant covariance of disturbances to the output and inflation equations.

Given that the results of our specification tests indicated $A R C H$, at least for the inflation equation, we proceed to specify and estimate such a model. Since our concern is the effect of the variance of inflation on output growth, we allow the variance of inflation to enter the equations for inflation and output growth. As a further check of the specification, we also allow the variance of output growth to enter the inflation and output growth equations. That is, we specify an $A$ RCH-M model. We can then directly estimate and test the hypotheses of interest.

7Further evidence may be obtained by looking at related series, Money and velocity are related to the inflation series and output growth in a known way. We present evidence in table 1 that M1 money growth and velocity growth (defined as the first difference of the log of nominal GNP minus the $\log$ of $\mathrm{M} 1$ ) do not contain a unit root. Since the growth rate of velocity is, by definition, output growth plus inflation minus money growth, the growth rate of velocity should exhibit the properties of the component series. As Engle and Granger (1987) write, "Because of the relative sizes of the variances, it is always true that the sum of an l(0) and an (1) will be l(1)" (p. 253). Thus, velocity growth as a linear combination of inflation, money growth and output growth should be l(1), or integrated of order $t$, if any of the component series are (1). Since the evidence indicates that the growth of velocity does not contain a unit root, i.e., is l(0), this is indirect evidence that inflation is also (r). The only exception would be if

\section{Table 2}

\section{VAR Model of Output Growth and Inflation Sample: 1/1960-11/1988}

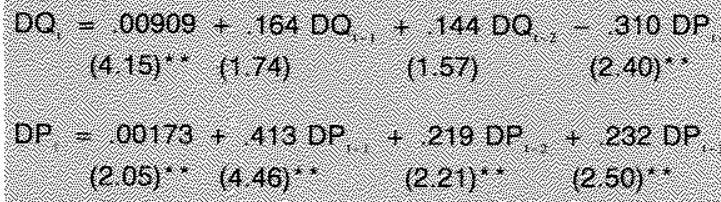

Where the vartance covariance hathx or the disturbances is estinated to 6

Vareat $=1,8610^{\circ}$

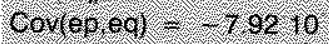

Var(ep) $=8.73 .10$

\section{and we log thellood value 680 .}

hicates signicance an he 5 percent level

The bivariate ARCH-M model for inflation (dp) and real output growth (dq) that we estimate is given as: ${ }^{10}$

(1) $d p_{t}=\beta_{10}+\beta_{13} d p_{1-1}+\beta_{12} d p_{t-2}+\beta_{13} d p_{t-3}$

$$
+\beta_{14} H_{p, 2}+\beta_{15} H_{q, t}+\varepsilon_{p, t}
$$

(2) $\mathrm{dq}_{t}=\beta_{20}+\beta_{21} \mathrm{dq}_{\mathrm{t}-1}+\beta_{22} \mathrm{dq}_{\mathrm{t}-2}+\beta_{23} \mathrm{dp}_{\mathrm{t}-1}$

where

$$
\beta_{24} H_{p, t}+\beta_{25} H_{4, t}+\varepsilon_{q, t}
$$

$$
\text { (3) } \begin{aligned}
\mathrm{H}_{p, t} & =\alpha_{10}+\alpha_{11}\left[\sum_{i=1}^{4}(5-\mathrm{i}) \varepsilon_{p, t-1}^{2} / 10\right] \\
& +\alpha_{12}\left[\sum_{i=1}^{4}(5-\mathrm{i}) \varepsilon_{q, t-1}^{2} / 10\right]
\end{aligned}
$$

the variables money, output and inflation were cointegrated. Tests of cointegration failed to detect such a relationship. Thus, we find that the intlation series is highly persistent, but not nonstationary.

8This approach was first suggested by Akaike (1969). Hsiao (1981) presents a strategy for applying the technique in a multivariate selting.

9This year also approximately divides the sample into the fixed or managed exchange-rate period before 1973 and the relatively flexible exchange-rate period after 1973 , as well as dividing the sampie into the pre-1973 period of no oll price shocks and the post-1973 period marked by a number of ofl price shocks, both positive and negative.

${ }^{10} \mathrm{~A}$ demmy variable for the price-control period, laking the value of 1 when the controls were in place during 1I//1971-1/1973. Was found to be statistically insignificant. 


\section{Table 3}

\section{Diagnostic Tests on VAR \\ Sample: $1 / 1960-11 / 1988$}

\section{A. Test for serial conrelation}

\begin{tabular}{|c|c|c|c|c|}
\hline $\begin{array}{l}\text { order of } \\
\text { serial. } \\
\text { correlation }\end{array}$ & $\begin{array}{l}\text { oppougr } \\
\text { trest } \\
\text { statistic }\end{array}$ & $\begin{array}{l}\text { Wh equation } \\
\text { Mrginal } \\
\text { signifucance }\end{array}$ & $\begin{array}{l}\text { Thriatic } \\
\text { prost } \\
\text { statistic }\end{array}$ & 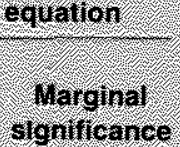 \\
\hline $\begin{array}{l}1 \\
2 \\
3 \\
4\end{array}$ & $\begin{array}{l}0.15 \\
0.15 \\
2.22 \\
2.33\end{array}$ & $\begin{array}{l}10 \\
63 \\
68 \\
68\end{array}$ & $\begin{array}{l}129 \\
161 \\
218 \\
2.18\end{array}$ & $\frac{4}{4}$ \\
\hline
\end{tabular}

B. Test for ARCH

Single equation tests

\begin{tabular}{|c|c|c|c|c|c|c|}
\hline \multirow[b]{2}{*}{$\begin{array}{l}\text { order of } \\
\text { Anch }\end{array}$} & \multicolumn{2}{|c|}{ outuvo gowh varance } & \multicolumn{2}{|c|}{ nilanon vartance } & \multicolumn{2}{|c|}{$\begin{array}{l}\text { Govariance, output } \\
\text { grovith and infirion }\end{array}$} \\
\hline & $\begin{array}{l}\text { Test } \\
\text { statistic }\end{array}$ & $\begin{array}{l}\text { Warginal } \\
\text { Srgilicance }\end{array}$ & $\begin{array}{l}\text { Test } \\
\text { stantstic }\end{array}$ & $\begin{array}{l}\text { Varginal } \\
\text { slgnifeance }\end{array}$ & $\begin{array}{l}\text { Test } \\
\text { staistic }\end{array}$ & $\begin{array}{l}\text { Narginal } \\
\text { significance }\end{array}$ \\
\hline 1) & 0.05 & 82 & 031 & 86 & O.00 & 88 \\
\hline 2 & 10.07 & 96 & 0.3 & 86 & 201 & 87 \\
\hline 3 & 145 & 69 & 1296 & 00 & $20=$ & 56 \\
\hline 4. & 207 & 12 & 1324 & 01 & 205 & 70 \\
\hline 6 & 221 & 90 & 16.94 & 82 & 6.22 & 76 \\
\hline 8. & 939 & 60 & 1105 & 63 & $4+11$ & 85 \\
\hline
\end{tabular}

\section{Test tor structural ehange}

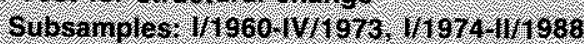

(4) $\mathrm{H}_{q, 1}=\alpha_{20}+\alpha_{21}\left[\Sigma_{i=1}^{4}(5-\mathrm{i}) \varepsilon_{p, t-i}^{2} / 10\right]$

$$
+\alpha_{22}\left[\sum_{\mathrm{i}=i}^{4}(5-\mathrm{i}) \varepsilon_{\mathrm{p}, \mathrm{s}-\mathrm{i}}^{2} / 10\right]
$$

and

$$
h_{\mathrm{r}}=\left|\begin{array}{ll}
\mathrm{H}_{\mathrm{p}, \mathrm{t}} & \mathrm{H}_{\mathrm{pq}} \\
\mathrm{H}_{\mathrm{pq}} & \mathrm{H}_{\mathrm{q}, \mathrm{l}}
\end{array}\right|
$$

This specification of the variance process, with the conditional variance modeled as a declining lag structure in the squared residuals, has been employed extensively in applications of the ARCH model, but it is restrictive. For example, this specification allows just one free parameter to be estimated on the four lagged squared residuals and imposes a linearly declin- ing lag structure. Therefore, other specifications of $\mathrm{H}_{p, 1}$ and $\mathrm{H}_{\mathrm{q}, \mathrm{s}}$ were tried. One alternative specification had separate coefficients on each of the four lags of $\varepsilon_{p, t}^{2}$ and $\varepsilon_{p, c}^{2}$. This alternative did increase the estimated log likelihood, but only the coefficients on $\varepsilon_{p, 1-3}^{2}$ and $\varepsilon_{q, t-3}^{2}$ were statistically significant. Further, a likelihood ratio test between the model with only $\varepsilon_{p, 3-3}^{2}$ and $\varepsilon_{q, t^{-3}}^{2}$ affecting the variance of inflation and output growth, respectively, and a model with all four lags of $\varepsilon_{\mathrm{p}, t}^{2}$ and $\varepsilon_{\mathrm{q}, r}^{2}$ in the respective variance equations, indicated no support for the additional lags. Also, lagged $H_{p, t}$ and $H_{q, 1}$ were added to the variance specifications yielding the generalization of the ARCH model called GARCH) and again the estimated log likelihood function did not increase significantly. 


\section{Table 4}

\section{ARCH-M Model of Output Growth and Inflation Sample: 1/1960-11/1988}

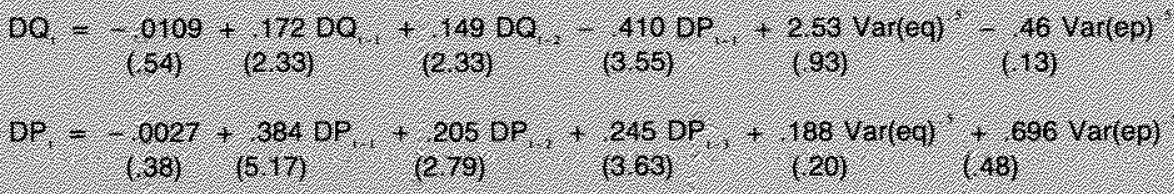

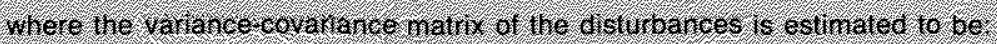

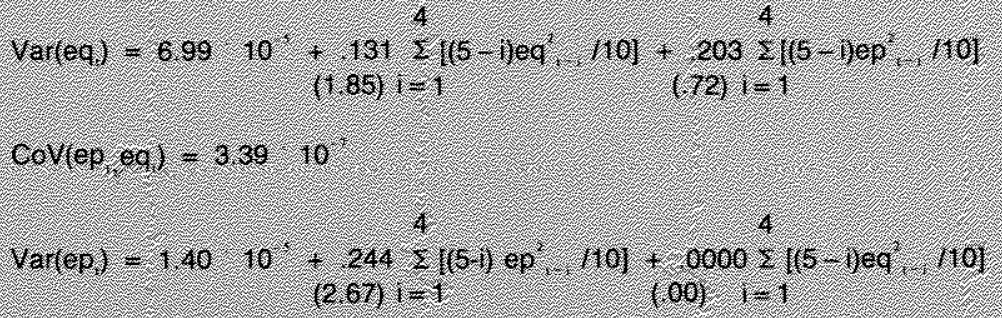

Estimates of the model in equations 1-4 are reported in table $4 .{ }^{11}$ The coefficients on the conditional variance terms entering the output growth and inflation equations are insignificant at the 5 percent level. In addition, the lags of the output growth residuals have an insignificant coefficient in the inflation variance equar tion. Moreover, the lags of the inflation residuals have an insignificant coefficient in the output variance equation. Finally, a likelihood ratio test of the model reported in table 4 against the homoskedastic model reported in table 2 indicates that the null hypothesis, that the homoskedastic model is a valid restriction to the ARCH-M model, cannot be rejected at any reasonable significance levels. These results indicate that inflation uncertainty, measured as the conditional variance of inflation from an ARCH specification, does not have a significant effect on output growth.
To determine the sensitivity of the results to the model specification, we modified the model to include only the third lag of the squared in. flation residual in the inflation variance equation and only the third lag of the squared output growth residual in the output variance equation. This specification was chosen from a preliminary model including separate coefficients on each of the four lags of the squared residuals in each variance equation. Estimates are reported in table 5 . The estimated log likelihood function of this specification is nearly equivalent numerically (and certainly not statistically distinguishablel from the more general model. A likelihood ratio test against the homoskedastic VAR model leads to rejection at the 5 percent significance level of the null hypothesis that the homoskedastic VAR restrictions are correct relative to the ARCH-M alternative. ${ }^{12}$
tTo estimate the ARCH $\sim \mathrm{M}$ model, indeed all the ARCH estimates reported in this paper, the ARCH parameters $\alpha_{11}, \alpha_{12}, \alpha_{21}$ and $\alpha_{22}$ were restricted to be non-negative. The shaded insert discusses the rationale for this restriction.

${ }^{12}$ One caveat to the interpretation of the likelihood ratio tests reported here, indeed to most of the statistical inference drawn in this paper, is that considerable pretesting was done in specifying both the VAR and ARCH models. This greatly complicates the inference problem. A good introduction to this issue is provided in Judge, et al (1988). 


\section{Table 5}

ARCH-M Model of Output Growth and Inflation Sample: V/1960-11/1988

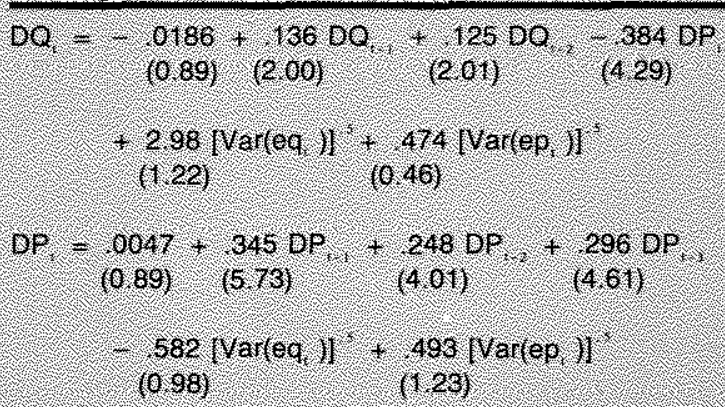

The estimated parameter values and the asymptotically valid t-statistics reported in table 5 provide further information about the hypotheses of interest. Table 5 shows that the variance of inflation had a positive but statistically insignificant effect on the rate of growth of output and a positive but statistically insignificant effect on the rate of inflation. These results provide no support for the hypotheses under investigation. We also find that the variance of output has an insignificant positive effect on the rate of growth of output and an insignificant negative effect on the rate of inflation.

Table 5 also reports estimates of the variance process. The third lag of squared realizations of the stochastic error in the inflation equation has a statistically significant effect on the condition. al variance of the inflation error. In contrast, the lagged squared realization of the stochastic error in the output growth equation has a statistically insignificant effect on the conditional variance of output growth.

Table 5 provides no support for the hypotheses that inflation uncertainty, measured as the conditional variance of inflation forecast errors, has a negative effect on output growth. Indeed, of the six coefficients estimated for the ARCH-M model that were not estimated for the homoskedastic VAR model, five were statistically insignificant, including all of those measuring the effect of the conditional variance of inflation on the inflation rate and the rate of output growth. This observation leads to the suspicion that it is only the ARCH process itself that is im. portant in the rejection of the VAR restrictions by the likelihood ratio test, a suspicion confirmed by estimation of an ARCH variant of the model in table 6 . The ARCH model includes the conditional variance specification as in table 5 , but does not allow the conditional variance to affect the conditional mean of the inflation pro. cess or the rate of output growth. Estimates of this model are reported in table 6 .

In table 6 we see that the likelihood value is almost as high as that reported in table 5. A likelihood ratio test does not reject the null hypothesis that the ARCH model is a valid restriction to the ARCH-M model. Moreover, a likelihood ratio test of the null hypothesis of the 


\section{Table 6}

\section{ARCH Model for Output Growth and Inflation}

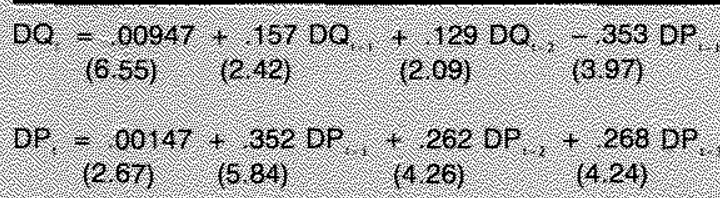

and lhe log likeinood value s 6809

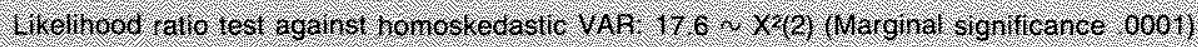

homoskedastic VAR model against the $\mathrm{ARCH}$ alternative leads to a strong rejection of the null. It seems that the inflation-output growth process has ARCH disturbances, but that the changing conditional variance does not feed back to the inflation rate or the rate of output growth.

\section{PUPTIDER PROELEMS RND PROSPECTS}

The evidence presented here lends no support to the hypothesis that uncertainty about the future inflation rate leads to a reduction in the rate of output growth. Further, this evidence, in accord with that provided by both Katsimbris and Thornton using an alternative methodology, casts doubt on the existence and relevance of the hypothesized positive relation between the rate of inflation and the uncertainty about future inflation.

One possible explanation for this lack of support is that the inflation rate was largely predictable over our sample. Indeed, it is difficult to detect much of an ARCH effect in the inflation data over this span, especially when the inflation forecasting equation is supplemented with other exogenous variables, most notably relative energy prices. Several recent studies, including Engle (1983), Holland (1984), Cosimano and Jansen (1988), and Rich, Kanago and Raymond
(1988), all report either difficulty in detecting ARCH in the inflation equation or estimates of the ARCH conditional variance that are very flat over this period. This study identifies an ARCH inflation process, but the process may not have been sufficiently variable to generate precise measures of the effect of the conditional variance of inflation on output growth.

Because this study is limited to investigating the first two moments of the bivariate inflation rate-output growth rate process, it abstracts from some potentially important issues, one of which is the importance of relative energy prices after the 1973 oil price shock. Of perhaps more importance is the neglect of a measure of the mean and variance of the policy stance of the monetary authority. Uncertainty about the future inflation rate can arise from several sources, including uncertainty about future government policy or future values of exogenous variables impinging on the inflation rate. $A$ measure of government policy, perhaps by some monetary aggregate, might be useful to supple. ment results from the bivariate system reported here.

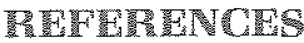

Akatke, Hizotogu. "Fitting Autoregressive Models tor Predic" tion," Annals of the institute of Statistical Mathematics (January 1969), pp. 243-47. 
Blejer, Mario I., and Leonardo Leiderman. "On the Real Effects of Inflation and Relative Price Variability: Some Empirical Evidence," Review of Economics and Statistics (November 1980), pp. 539-44.

Bollerslev, Tim. "Generalized Autoregressive Conditional Heteroskedasticity," Joumal of Econometrics (April 1986), pp. $307-27$.

Cosimano, Thomas F., and Dennis W. Jansen. "Estimates of the Variance of U.S. Inflation Based upon the ARCH Moded: Comment," Journal of Money, Credit, and Banking (August 1988, Part 1), pp. 409-21.

Coulson, N. Edward, and Russell P. Robins. "Aggregate Economic Activity and the Variance of inflation: Another Look," Economic Letters (January 1985), pp. 71-75.

Cukierman, Alex. "Relative Price Variability and Inflation: $A$ Survey and Further Results:" Cannegie-Rochester Series on Public Policy (Autumn 1983), pp. 103-58.

Cukierman, Alex, and Paul Wachtel. "Differentia Inflationary Expectations and the Variability of the Rate of Intlation: Theory and Evidence." American Economic Review (September 1979), pp. 595-609.

Dickey, David A., and Wayne A. Fulter. "Likelihood Ratio Statistics for Autoregressive Time Series with a Unit Root," Econometrica (July 1981), pp. 1057-72.

"Distribution of the Estimators for Autoregressive Time Series with a Unit Root," Joumal of the American Statistical Association (June 1979), pp. 427-31.

Engle, Robert F. "Estimates of the Variance of U.S. Inflation Based upon the ARCH Model," Journal of Money, Credit, and Banking (August 1983), pp. 286-301.

"Autoregressive Conditional Heteroskedasticity with Estimates of the Variance of United Kingdom Intlation," Econometrica (July 1982), pp. 987-1008.

Engle, Robert F., and C. W. J. Granger. "Co-fntegration and Error Correction: Representation, Estimation, and Testing," Econometrica (March 1987), pp. 251-76.

Engle, Robert F. David M. Litien, and Russell P. Robins. "Estimating Time Varying Risk Premia in the Term Siructure: The ARCH-M Model:" Econometrica (March 1987), pp. $391-407$

Evans, Paul. "Price-Level instability and Output in the U.S.", Economic Inquiry (April 1983), pp. 172-87.

Fischer, Stanley. "Towards an Understanding of the Costs of Inflation: II,"Carnegie-Rochester Conference Series on Public Policy (Autumn 1981), pp. 5-42.

Friedman, Milton. "Nobel Lecture: Inflation and Unemploy" ment," Joumal of Political Economy (June 1977), pp. 451-72.

Froyen, Richard T, and Roger N. Waud. "An Examination of Aggregate Price Uncertainty in Four Countries and Some Implications for Real Output;" International Economic Review (June 1987), pp. 353-72.
Gale, William A. "Temporal Variablity of United States Consumer Price Index," Journal of Money, Credit, and Banking (August 1981), pp 273-97.

Godtrey, L. G. "Testing Against General Autoregressive and Moving Average Error Models when the Regressors $1 \mathrm{n}$ clude Lagged Dependent Variables," Econometrica (November 1978), pp. 1293-130t.

Hafer, R. W. "Inflation Uncertainty and a Test of the Friedman Hypothesis," Journal of Macroeconomics (Summer 1986), pp. 365-72.

Holland, A. Steven. "Does Higher Inflation Lead to More Uncertain Inflation?" this Review (February 1984), pp. 15-26.

Hsiao, Cheng. "Autoregressive Modelling and Money-lncome Causality Detection," Journal of Monetary Economics (January 1981), pp 85-106.

Judge, George G., R. Carter Hill, William E. Griffiths, Helmul Lutkepohl, and Tsoung-Chao Lee. Introduction to the Theory and Practice of Econometrics (John Wiley and Sons, 1988).

Katsimbris, George M. "The Relationship between the Inflation Rate, Its Variability, and Output Growth Variability: Disaggregated International Evidence," Journal of Money, Credit, and Banking (May 1985), pp. 179-88.

Logue, Dennis E, and Richard J. Sweeney. "Inflation and Real Growth: Some Empirical Results," Joumal of Money, Credit, and Banking (November 1981), pp. 497-501.

Marshall, Alfred. "Answers to Questions on the Subject of Currency and Prices Circulated by the Royal Commission on the Depression of Trade and Industry." Official Papers of Alfred Marshall (London: McMillan, 1926).

Mullineaux, Donald J. "Unemployment, Industrtal Production, and Inflation Uncertainty in the United States," Review of Economics and Statistics (May 1980), pp. 163-69.

Okun, Arthur M. "The Mirage of Steady Inflation," Brookings Papers on Economic Activity (2: 1971), pp. 485-98.

Pagan, A. R., A. D. Hall, and P. K. Trivedi. "Assessing the Variability of Inflation," Review of Economic Studies (October 1983), pp. 585-96.

Rich, Robert W. Bryce Kanago, and Jennie Raymone. "New Evidence on the Variance of U.S. Inflation Based Upon the ARCH Model," Vanderbilt University Working Paper No. 88-W06, October 1988

Schmidt, Peter. "Dickey-Fuller Tests with Drift," unpublished manuscript, Michigan State University, June 1988.

Taylor, John B. "On the Relation between the Variability of Inflation and the Average Inflation Rate," CamegieRochester Series on Public Policy (Autumn 1981), pp. 57-85.

Thornton, John. "Inflation and Output Growth: Some Time Series Evidence, A Note," American Economist (Fall 1988), pp 55-58. 